\title{
Cross-friend effects on entry into marriage and parenthood: A multiprocess approach
}

\author{
Nicoletta Balbo, Policy Analysis and Public Management Department and Dondena Centre, \\ Bocconi University, Milan, Italy
}

Nicola Barban, Department of Sociology and Nuffield College, University of Oxford, Oxford, UK

Melinda C. Mills, Department of Sociology and Nuffield College, University of Oxford, Oxford, UK

Corresponding author: Nicoletta Balbo. Policy Analysis and Public Management Department and Dondena Centre. Bocconi University. Via Guglielmo Rontgen 1, 20136, Milan, Italy. Phone: +39 02 5836 5535. Email: balbo.nicoletta@unibocconi.it

\begin{abstract}
This paper aims to investigate whether friends' and peers' behavior influences an individual's entry into marriage and parenthood of young adults in the United States. After first studying entry into marriage and parenthood as two independent events, we then examine them as interrelated processes, thereby considering them as two joint outcomes of an individual's unique, underlying familyformation strategy. Using the National Longitudinal Study of Adolescent Health, we engage in a series of discrete time event history models to test whether the larger the number of friends and peers who get married (or have a child), the sooner the individual gets married (or has a child). Results
\end{abstract}


show strong cross-friend effects on entry into parenthood, whereas entry into marriage is only affected by more general contextual effects. Estimates of a multiprocess model show that cross-friend effects on entry into parenthood remain strongly significant even when we control for cross-process unobserved heterogeneity. 


\section{INTRODUCTION}

Research on the impact of peer and social interaction effects on demographic behavior has focused almost exclusively on fertility (Kohler et al., 2002; Kohler et al., 2006). Diffusion and social interaction approaches (Bongaarts \& Watkins, 1996; Montgomery \& Casterline, 1996) have emphasized that fertility decision-making is affected not only by the individual's or couple's characteristics and the socio-institutional context, but also by relevant others' behaviors. However, research on social interaction effects on family-formation behaviors other than fertility is virtually absent, although the same theoretical considerations regarding the importance of social interaction could most certainly be applied to other demographic behaviors, such as marital decisions.

In the current study, we aim to extend existing research on social interaction effects by investigating to what extent friends' behavior can influence the entry into marriage and parenthood during the transition to adulthood. In the demographic and sociological literature, entry into marriage and parenthood have been established as closely interrelated events, both in terms of their timing (Manning, 1995; Rindfuss et al., 1988) and the life planning they imply (Liefbroer, 1999). Some studies have specifically addressed the issue of spuriousness of the relationship between these two processes (Baizan et al., 2003, 2004; Lillard, 1993; Steele et al., 2005, 2006; Upchurch et al. 2002). In an attempt to uncover the causal nature of the relationship between marital and fertility decisionmaking, this body of research has highlighted how inter-individual differences in subjective dimensions might affect both demographic processes.

Building upon and extending previous research, we introduce two main contributions to the field. First, we investigate how social interaction might impact entry into marriage and parenthood differently. We extend existing literature examining friends' and peers' effects on two different familyformation behaviors (i.e., marriage and childbearing). Our second contribution rests with the fact that we do not only consider entry into marriage and parenthood as two independent transitions, but also as two joint outcomes of an individual's unique, underlying family-formation strategy. Our aim is then to uncover whether cross-friend interactions affect the interrelated decisions of getting married 
and having a child. In this way, we provide a unique contribution to the existing research, which until now has investigated only the effect of social interaction on isolated life-course outcomes (mostly fertility choices, such as cross-sibling effects on fertility, Lyngstad \& Prskawetz, 2010).

The central research questions that this paper aims to answer are, therefore: Do cross-friend interactions affect both the entry into marriage and parenthood, or do they only influence one of the two processes? To what extent are the peer effects on fertility found in existing literature affected by possible preceding cross-friend effects on marriage and the presence of common unobserved heterogeneity?

Our study focuses on the study of young adults in the American context, following them from age 15 until around age 30 . The transition to adulthood in the United States is particularly interesting to investigate as there have been substantial changes in family formation behaviors in recent years (Ryan et al., 2009). Whereas in 1970 the median age at first marriage for women was 20.8 and first birth was 21.4, in 2008 they reached 25.9 and 25 (CDC/NCHS, National Vital Statistics System; Current Population Survey, U.S. Census Bureau). It is therefore relevant to uncover whether peer effects shape an individual's marital and childbearing decisions to then determine whether social interactions might also play a role in these macro-level, postponement trends. Young adults are, moreover, an ideal group for studying cross-friend effects since research shows that peer social networks have a particularly strong influence on an individual's behaviors during early adulthood (e.g., Ali \& Dwyer, 2010; Christakis \& Fowler, 2007; Knecht et al., 2010; Pollard et al., 2010).

\section{BACKGROUND}

There is a growing acknowledgment of the importance of the social network for an individual's behavior. Previous empirical applications within demography have examined the impact of social influence and learning on contraceptive and reproductive choices in developing countries (Behrmanet al., 2002; Kohler et al., 2001). Although additional empirical research has recently emerged, it remains limited due to the lack of suitable network data and the complexity of the analysis required to identify social interaction effects and disentangle them from confounding effects. Until now, next 
to the qualitative work of Bernardi and colleagues (e.g., Bernardi, 2003; Bernardi et al., 2007; Keim et al., 2009), which provided relevant insights into how social influence and learning operate to impact fertility choices in advanced societies, some recent studies adopted a quantitative approach to examining fertility outcomes. They empirically demonstrated that social interactions among siblings (Kuziemko, 2006; Lyngstad \& Prskawetz, 2010), co-workers (Ciliberto et al., 2010; Hensvik \& Nilsson, 2010), friends (Balbo \& Barban, 2014), and peers belonging to the same ethnic-religious group (Manski \& Mayshar, 2003) shape an individual's fertility decisions.

Although it is plausible that social interactions affect demographic behavior beyond fertility, research is limited. To our knowledge, only a handful of studies examined peer effects on union formation. Hernes (1972) developed a macro-level diffusion model of age at marriage, showing that the greater the share of married peers within a cohort, the higher the propensity to marry for individuals in such a cohort. Whereas Hernes assumed that members of the same cohort constitute the influential peer group, Drewianka (2003) instead identified people living in the same geographical area (i.e., county) as the relevant peer group. Here the assumption was that an increase in the fraction of single persons aged 16 to 44 in a certain geographical area leads to a decrease in the propensity to marry for an individual living in that area.

An alternative approach is the use of agent-based models and simulated data to examine how social interdependencies shape, respectively, marital and fertility decisions (Aparicio Diaz et al., 2011; Billari et al., 2007). Although these simulations have the undeniable shortcoming that they $a$ priori assume peer effect influences at the micro level, they offer the ability to assess to what ex tent macro dynamics in demographic behavior can be explained by social interaction at the individual level. Aparicio Diaz et al. (2012), for instance, found that accounting for social interactions in an agent-based model can explain the shift in fertility rate observed in Austria between 1984 and 2004.

\section{Theoretical Framework}

To understand how cross-friend interactions might influence family formation, we can draw on two bodies of literature. The sociological and demographic literature has identified two processes through 
which relevant others (e.g., relatives, friends, colleagues) matter for fertility choices: social influence and social learning (e.g., Kohler et al., 2001; Montgomery \& Casterline, 1996). Social influence refers to consensus in peer groups that constrains attitudes and behaviors, whereas social learning relates to how individuals gain knowledge from others.

Economic research has instead underlined the importance of cost-sharing dynamics as a potential mechanism explaining peer effect on fertility choices (Kuziemko, 2006). Katz \& Shapiro (1985) refers to cost-sharing dynamics to identify the opportunity for people "consuming" the same kind of experience (or good) to share the costs and uncertainty associated with it.

We expect that friends might influence an individual's risk of both getting married and becoming a parent, although we believe that the main mechanisms via which such an influence occurs are different for the two life transitions. These two events indeed bring about different levels of costs and lifestyle changes, with entry into parenthood having deeper implications than marriage.

Entry into marriage. In contemporary U.S. society, marriage has become less normative and widespread than in the past (Cherlin, 2005; Manning \& Smock, 1995; Uecker \& Stokes, 2008). At the same time, cohabitation has been increasing (Kennedy \& Bumpass, 2008; Ryan et al., 2009; Smock et al., 2008), becoming the modal path to marriage (Huang et al., 2011). Young people largely view cohabitation as a pre-marital stage, not as a substitute for marriage (Manning et al., 2007). In this study, we examine only marriage and not cohabitation for both substantive and practical reasons. The primary reason is that it is less theoretically plausible that friends and peers influence the entry into cohabitation as opposed to marriage. Although cohabitation is increasingly widespread (Kennedy \& Bumpass, 2008), it still lacks the strong symbolic meaning attached to marriage. Cohabitation decisions in the U.S. have been shown to be driven by practical reasons (e.g., to reduce living costs), with individuals often 'sliding' into cohabitation in a more diffuse manner (Stanely et al., 2006). For practical reasons as well, cohabitation is not included in this study. Since cohabitation and marriage are not mutually exclusive, it is not possible to identify the specific cross-friend influence on the different family formation patterns. 
Assuming that a large portion of young adults get married after already co-residing with their partner, or having experienced cohabitation with a former partner, the transition to marriage should not bring about a high degree of uncertainty, costs, or considerable life changes. Therefore we do not expect that cross-friend effects primarily work via cost-sharing strategies or learning processes. Rather, people may be positively influenced by their friends who get married, mainly because of social influence mechanisms that lead people to conform to their friends (Nazio \& Blossfeld, 2003). Social influence might work via social comparison and social norms. According to the theory of social comparison (Festinger, 1954), individuals adapt their behavior to those who are deemed as being in a similar social position or who share similar characteristics. Since people tend toward homophily, in that they bond with similar others (McPherson et al., 2001), they are likely to conform to the behavior of their friends. In this way, friends define normative conduct, or, in Cialdini's and colleagues' (1990) words, certain descriptive norms, which is 'what is typical or normal, thus, what most people do', and consequently what becomes 'sensible to do'. Building on this, we expect that the higher the number of friends who are married, the greater an individual's risk of entry into marriage (H1).

Entry into parenthood. We believe that cross-friend effects on fertility likely operate mainly via social learning mechanisms and cost-sharing dynamics. Compared to getting married, having a child brings about more uncertainty and costs (monetary ones, such as foregone earnings and opportunity costs in terms of a professional career, as well as non-monetary ones, such as relational costs) (Balbo \& Barban, 2014; Mills et al., 2011). Having friends with children, with whom an individual can share his or her experience as a parent, might reduce the uncertainty associated with it because friends can offer behavioral examples and provide relevant information on how to face the transition to parenthood and deal with the substantial life changes it brings about (Bernardi, 2003). Moreover, going through such a unique life transition as the only person within a peer group likely leads to higher relational costs. Becoming a parent is a radical change in one's life that strongly impacts the amount and the nature of leisure time, and thereby time spent with friends. Therefore, having the 
opportunity to experience parenthood together with other friends makes this transition less relationally costly, because life changes within a social group are synchronized (or anyway shared) and the risk of being left alone or lagging behind is reduced. Based on this, we pose the following hypothesis: The higher the number of friends who have a child, the greater an individual's risk of becoming a parent $(\mathrm{H} 2)$.

Simultaneous influences on entry into marriage and parenthood. As multiple studies have shown, young adults continue to see a stable union as the optimal and appropriate setting for having a child (Hobcraft \& Kiernan, 1995; Kiernan, 1999; Manning \& Smock, 1995; Smock \& Greenland, 2010; Thomson et al., 2012). Entry into parenthood happens more frequently for those in a co-residential partnership, especially a marriage, compared to those who are single (Baizan et al., 2004). However, a body of research has highlighted that this association might be spurious, and therefore the sequence of events (e.g., first partnership and then parenthood) might not reflect a causal relationship. If living together with a partner increases the risk of having a child, the willingness to become a parent might accelerate the decision to form a union (Brien et al., 1999; Baizan et al., 2003, 2004). Put differently, there might be some common unobserved subjective factors that simultaneously affect both familyformation decisions (Aassve et al., 2006).

For this reason we therefore consider entry into marriage and parenthood as two joint outcomes of an individual's unique, underlying family-formation strategy. This strategy is influenced not only by unobserved personal family predispositions and attitudes, but also by unmeasured social norms, influence, and pressure that an individual is exposed to within her social network. We envision these unobserved forces to influence both marital and parental decisions in a concordant way (e.g., either positively or negatively impacting both processes), leading people to choose consistent family formation paths over their life course. In line with this argument, we therefore expect that the risk of entry into marriage and having a first child might be partially determined by common individual factors, which are positively correlated (H3).

Our ultimate goal is to uncover whether cross-friend effects on fertility, which have been found 
in previous research (Balbo \& Barban, 2014), are actually at play even when we take into account possible preceding cross-friend influence on the transition to marriage, and control for common interindividual heterogeneity affecting both marital and fertility decisions. For this reason, we focus on a demographic pathway in which an individual first experiences marriage, followed by parenthood.

It is very difficult to argue theoretically and a priori anticipate how cross-friend effects on fertility might be affected by these factors, the presence of which must be determined in the first place. It may, for instance, be that most of the cross-friend influences occur via marriage, with individuals positively affected by friends who get married, thereby entering into matrimony themselves. Cross-friend effects on an individual's risk of having a child might, therefore, simply be the consequence or side-effect of the influence of a previous marriage by a friend. If this is the case, once marriage and childbearing are investigated as joint decisions, the friend effect on childbearing might be lower or negligible. We opted to engage in an exploratory analysis without postulating any specific hypothesis, in line with the approach adopted by Steele and colleagues (2005).

\section{DATA AND METHOD}

\section{Data and sample}

The data we use come from all of the four waves of the National Longitudinal Study of Adolescent Health (Add Health, http://www.cpc.unc.edu/projects/addhealth), a panel study of a nationally representative sample of adolescents in the United States who were in grades 7 through 12 in Wave I (1995). The Add Health cohort (born between 1976 and 1982) has been followed into young adulthood with four in-home interviews (Wave I in 1995, Wave II in 1996, Wave III in 2001-02, and Wave IV in 2008-09), at the end of which the sample was between 24 and 32 years old. Add Health provides us with the unique opportunity to make use of and combine three different types of information: longitudinal data on respondents' socio-economic, psychological, and physical characteristics; their life course events and trajectories; and data on social context and networks (e.g., family, school, friendships, peer groups). Therefore, these data are optimal for our purposes, that is, investigating the impact of social interaction among friends on the transition to marriage and 
parenthood.

We restrict our sample to women only, not younger than 15 years old, who are observed until around age 30 . The decision to exclude men from our analysis rests with substantial data limitations. As already documented by Schoen et al. (2007) and Amato et al. (2008), there is a systematic misreporting of childbirths in the fertility history modules. This underreporting of male fertility has also been found in other large surveys (e.g., Joyner et al., 2012). However, while we could make use of the information in the household roster to adjust omitted fertility data for women (Schoen et al., 2007), this was impossible for men. Therefore, men were excluded from the study sample.

In Wave I, in-home and in-school questionnaires were administered to 20,745 respondents. In the latter questionnaire, in-school network information was collected and up to 10 friendship ties for each respondent were identified. In Wave III, a follow-up to the Wave I network module (from now on called friends module) was administered to 3,572 respondents who were in $7^{\text {th }}$ and $8^{\text {th }}$ grades at Wave I. Since we included only women in our study, our final sample consists of 1,903 individuals. Because we also make use of information collected in Wave IV, women who dropped out after Wave III $(\mathrm{N}=177)$ are part of our sample but are considered as right censored after Wave III. In the friends module of Wave III, respondents were asked a battery of questions about the current relationship (or lack thereof) with 10 former schoolmates. These 10 people were selected into a respondent's questionnaire by a name generator based on the probability of remaining friends with that respondent (for further details, see Balbo \& Barban, 2014). Every selected schoolmate was also a respondent in the previous Waves, as well as in the in-home survey at Wave III. Among the 10 former schoolmates of each respondent, we excluded men (for the same reason we included only women in our sample, see above) and those who were identified as kin (e.g., cousins, siblings) in order to focus specifically on former schoolmates who were not part of the family network. Using information on friendship status at Wave III, we defined two categories of the network relationship for each respondent: peers, who are former schoolmates who have never been identified as friends, throughout Waves I and III; and friends, who are former schoolmates who became friends at Wave I and have remained so over 
time, at least until Wave III. As we explain in the next sub-section, such distinction between peers and friends is part of our identification strategy, in order to disentangle contextual effect from crossfriend influence.

Former friends who used to be respondent's friends but were not anymore at Wave III were excluded from the respondent's list of 10 former schoolmates. This was done because of the lack of reliable information on the length of friendship, which would not allow us to analyze the pattern of influence of former friends. The friendship network we could draw for each respondent using the friends module of Wave III represents only a partial view of an individual's entire friendship network. However, we assume that the partial network of friends from early adolescence is a representative selection of an individual's entire friendship network during early adulthood, which has been shown by previous longitudinal studies (e.g., Chang et al., 2010).

Because we focus on individuals who first experienced marriage and then parenthood, we want to avoid any reverse causation of childbirth on marriage. We therefore censored individuals one month after the conception of their first child, thereby taking into account only transitions to marriage that occur before entry into parenthood. We extended the period of observation to one month after the time of conception because if marriage takes place within the same month in which a child is conceived, it is likely not the direct result of the pregnancy. If an individual does not experience the transition to parenthood, she is censored at the time of the last interview.

In our sample, each respondent has on average 3.5 peers and 0.8 friends. During the exposure time under examination, 713 respondents got married and 842 became parents. The median age at first marriage is 28 , while the age at conception is 26.7 .

In this study, we only focus on first marriage as well as first child for two main reasons. First, respondents are relatively young at Wave IV and therefore subsequent marriages and childbirths are rare events in our data (e.g., only $22.5 \%$ of our sample experiences higher parity before Wave IV). Second, as we look at recurrent episodes for each individual we would encounter what is defined in the econometric literature as 'reflection' issues (Manski, 1993). This refers to the difficulty of 
disentangling whether a friend's behavior is the cause or just the reflection of the individual's behavior. By looking only at first marriage and first birth, however, this problem does not seem to affect our analysis. By exploiting the panel design we have, we can assume that if the marital or fertility event of friends occurs before the one of the individual in question, the former can only be the cause of the latter, and not the reflection of something that has not yet happened. We decided to focus on marriage only and not also on cohabitation for several reasons. Since we are interested in the unobserved factors affecting union formation as well as first parenthood, it is more meaningful to look at the union episode in which the entry into parenthood is more likely to occur. While the link between first marriage and first birth is strong, given that the first marriage is the preferred setting in which to have the first child, this is not necessarily true for first cohabitation. Multiple cohabitation experiences are common before childbearing, but we are not able to take them into account because we do not consider recurrent events. Moreover, the majority of married couples in the United States experienced cohabitation before marriage, and cohabiting friends can influence both the respondent's decision to cohabit, as well as the decision to marry. This would lead us to analyze cohabitation and marriage as competing processes, making it very difficult to study the pattern of influence of friends on an individual's family formation behavior.

\section{Analytical strategy}

To answer our research questions and test our hypotheses, we developed an analytical strategy to tackle two main issues: (i) identification of cross-friend effects, disentangling them from contextual and selection effects; and (ii) study of entry into first marriage and parenthood not only as two independent events, but also as interrelated processes, simultaneously affected by common unobserved individual factors. In this section, we describe how we address these two issues, focusing on them one-by-one.

Strategy to identify interaction effects. To test empirically whether friends' behaviors have a positive influence on an individual's risk of getting married and becoming a parent, contextual and selection effects must be taken into account. The fact that friends act in a similar way might not necessarily be 
attributed (only) to cross-friend influence. Rather, two other mechanisms might operate as confounders. On the one hand, similarities in friends' behavior might be the result of the fact that friends live (and sometimes even choose to live) within the same social setting and are exposed to the same contextual forces and factors (Feld, 1981, 1982). On the other hand, since people tend to bond with individuals who are alike, similar behaviors might be the cause, and not the consequence, of preceding similar characteristics among friends (i.e., homophily, Lazarsfeld \& Merton, 1954; McPherson et al., 2001). Building upon the strategy developed by Balbo and Barban (2014) to disentangle confounding contextual effects from true cross-friend influence, we exploited the Add Health survey design, in particular information on the network structure from the friends module at Wave III. Similar to the strategy used by Elwert and Christakis (2008), who disentangle causation from shared-exposure bias in the 'widowhood effect' between spouses by examining both wives and ex-wives, we identified and distinguished between two different categories of an individual's former schoolmates: friends and peers. We considered as friends those who were identified as friends by the respondent at both Wave I and Wave III. We defined peers as those who were just former schoolmates of the respondent but have never been identified as friends. By including and estimating both types of ties in our analysis, we could distinguish between the effect of the shared social context (operationalized by peer effect) and the cross-friend interaction effect.

By virtue of the survey design, selection is a lesser issue in our analysis. Balbo and Barban (2014) showed that the two different strategies of either controlling for friendship selection using a simultaneous equation model in which the second equation estimates the probability of being friends, or simply assuming that friendship is exogenous to the family-formation decision-making, provide consistent results. We therefore assumed friendship to be exogenous to both marital and fertility decisions. Friendships and peer relationships under study were formed at the latest when respondents were around 12 to 15 years old (Wave I); therefore we could assume that their formation is exogenous to the decision to marry or become a parent. Put differently, the decision to become friends with someone is antecedent, and therefore independent, from marital and childbearing choices. It is highly 
unlikely that a 12-year-old adolescent chooses friends based on their family attitudes and orientations. Marriage and parenthood as two independent transitions. In our analysis, we first look at marriage and childbearing as two separate and independent life transitions. Only in a further step do we use a modeling strategy that simultaneously estimates entry into marriage and parenthood as dependent processes (see next sub-section).

We created an individual-month file, and, in order to be able to have the risk of marriage and parenthood as dependent variables, we computed two dummy variables that take on value 1 in the month within which the individual $i$ gets married or conceives (measured by subtracting 9 months from the time of delivery) and 0 in the preceding months for each respondent.

The two hazards of getting married and conceiving the first child during month $t$ for individual $i$ are estimated using two separate $c \log \log$ discrete time hazard functions. The hazard functions for the probability that the respondent $i$ gets married or pregnant at time $t$ are represented by $h_{i}^{m}$ and $h_{i}^{c}$ respectively, where:

$$
\begin{gathered}
\log \left[\log \left(1 \quad h_{i}^{m}(t)\right)\right]=D_{i}(t)+{ }_{1} X_{i}+{ }_{2} F_{i}^{m}(t)+{ }_{3} P_{i}^{m}(t)+{ }_{i} \\
\log \left[\log \left(1 \quad h_{i}^{c}(t)\right)\right]=D_{i}(t)+{ }_{1} X_{i}+{ }_{2} M_{i}^{c}(t)+{ }_{3} F_{i}^{c}(t)+{ }_{4} P_{i}^{c}(t)+{ }_{i}
\end{gathered}
$$

$D_{i}(t)$ is the baseline hazard, which in our case is a quadratic function at time $t$ of the individual $i$ 's duration (in age) between entry into the risk set (age 15) and the event under study (marriage or childbirth): $\alpha D_{i}(t)=\alpha_{0}+\alpha_{1}\left(a g e_{i}\right)+\alpha_{2}\left(a g e_{i}\right)^{2} . X_{i}$ represents a set of observed time-constant variables measuring individual $i$ 's observable characteristics that affect $i$ 's transition to marriage and first birth. $M_{i}^{c}(t)$, which is only present in the childbearing equation, is a time-varying covariate identifying whether and when individual $i$ is married. It takes on a value of 1 in the months in which the individual $i$ is married, and 0 otherwise. $F_{i}^{m}(t)$ and $P_{i}^{m}(t)$ are two additional time-varying variables indicating how many friends or peers, respectively, get married over time. $F_{i}^{c}(t)$ and $P_{i}^{c}(t)$ , in contrast, represent the time-varying variables measuring how many friends and peers become parents. In order to better capture cross-friend influence on fertility, we consider the birth of the 
friend's child, not the time of conception. However, we also tested whether the event was backdated up to 6 months at the start of the cross-friend influence, and did not find any substantial change in the estimates. For the sake of simplicity and to address multicollinearity issues, we assume that friends' marriage behavior only impacts an individual's risk of getting married (and not the risk of becoming a parent), and vice versa, that an individual's risk of having the first child is only affected by friends' fertility outcomes (and not by friends' marital outcomes).

To measure cross-friend effects, we drew upon the so-called Susceptible-Infected-Susceptible (SIS) model (e.g., Pastor-Satorrás \& Vespignani, 2001), used widely in epidemiological studies. As in the SIS model, we assumed the contagion to be linear on the absolute number of "infected" (i.e., married or parents) friends. This means that the probability of the individual $i$ 's "being infected" only depends on the number of "infected" friends, but not on the total number of friends the individual $i$ has. However, acknowledging that the total number of potential parents among friends is also dependent on the number of those identified as "still" friends at Wave III, we control for the friendship network size at Wave III (i.e., the total number of friends).

$\varepsilon_{i}$ and $\delta_{i}$ represent the unobserved time-invariant individual-specific factors influencing the risk of getting married and of having the first child, respectively. They are normally distributed random effects, with a zero mean and variance constrained to 1 . We had to fix the variance of the two processspecific random effects ( $\varepsilon_{i}$ and $\delta_{i}$ ) because we did not have repeated events for each individual $i$ that could bring enough intra-individual variation and therefore allow a proper identification of the random variables' variance. Following Baizan et al. (2003, 2004), we engaged in a sensitivity analysis of the estimates to assess the most appropriate values of the variance of these random effects. Based on that, we adopted a value of 1 for both variances of the two random effects.

Entry into marriage and parenthood as two interrelated processes: A multiprocess model. Until now, we have assumed that the entry into first marriage and entry into parenthood are two independent transitions, thereby constraining the correlation between the random variables of the two hazard functions to be zero. In order to estimate the two processes simultaneously and, thereby taking into 
account cross-process unobserved heterogeneity at the individual level, we engaged in a multiprocess system (Eq. 2):

$$
\left\{\begin{array}{c}
\log \left[-\log \left(1-h_{i}^{m}(t)\right)\right]=\alpha D_{i}(t)+\beta_{1} X_{i}+\beta_{2} F_{i}^{m}(t)+\beta_{3} P_{i}^{m}(t)+\varepsilon_{i} \\
\log \left[-\log \left(1-h_{i}^{c}(t)\right)\right]=\alpha D_{i}(t)+\beta_{1} X_{i}+\beta_{2} M_{i}^{c}(t)+\beta_{3} F_{i}^{c}(t)+\beta_{4} P_{i}^{c}(t)+\delta_{i}
\end{array}\right.
$$

in which the two random variables $\varepsilon_{i}$ and $\delta_{i}$ are assumed to have a joint bivariate normal distribution:

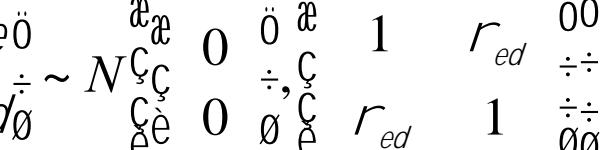

$\rho_{\varepsilon \delta}$ is the correlation between the unobserved heterogeneity terms of the two equations in the system (Eq. 2). We implemented the model using the software MLwiN 2.24, which performed the estimation using restricted maximum likelihood (RIGLS algorithm, Rasbash et al., 2004).

Following Lillard et al. (1995), Upchurch et al. (2002), and Steele et al. (2005), our multiprocess model is identified under the assumption that every source of correlation among the two processes under study are fully represented by cross-process correlation between individual-level residuals. Although we did not engage in a recurrent event model, by fixing the values of the variance of the two random variables $\varepsilon_{i}$ and $\delta_{i}$, our model could be identified without using any exclusion restriction. This model only includes the effect of previous marital outcomes on the fertility hazard, but does not include any structural effect of the hazard of having a child on the hazard of marriage transition. However, although not strictly necessary, our two equations do include covariates that specifically affect only one process (i.e., event-specific cross-friend effects). Moreover, following Baizan et al. (2004) once again, we also experimented with including the control variable measuring the number of siblings only in the fertility hazard and not in the hazard of marriage, but results did not change.

Covariates and control variables. In addition to controlling for unobserved time-invariant individual factors (by means of estimating random effects) and therefore preventing possible selection effects 
over time, we also included observable time-invariant as well as time-varying variables. We identified some factors that might confound cross-friend interaction effects on the risk of getting married and having a first child. Specifically, we controlled for relevant socio-demographic individual characteristics (measured at Wave I), namely race, parental education, income, religiosity, and family type. For race, we distinguished between Black and non-Black (in preliminary analyses we looked at Hispanics as a separate category, but because it was a small group and not significantly different from Whites, we merged Whites and Hispanics into one unique category). Parental education is identified using a dummy variable indicating when at least one parent has at least college education; parental income is measured using quintiles; parental religiosity is expressed by a dummy variable that takes on value 1 when parents state that they have gone to religious services at least once a week in the past year. Finally, family type is measured using a dummy variable that takes the value 1 in the case of an intact family (i.e., child is residing with both living parents at Wave 1) and 0 in the case of a singleparent family or step-family.

We also took into account the number of current friends at Wave III as a proxy for an individual's friendship network size, which might affect her social life and in turn her family formation strategy. Moreover, besides including age as a measure of the baseline time profile, which we assumed to be quadratic, we also included marital status as a time-varying covariate in the childbearing equation.

\section{RESULTS}

\section{Descriptive results}

Descriptive results provide initial interesting insights into which individual characteristics are associated with the transition to marriage and parenthood among young adults.

Table 1 reports descriptive statistics of the entire sample (last column), which we first investigated by dividing it into two sub-samples of women who experienced their first marriages within the observation period and women who remained unmarried by Wave IV ('marriage' columns in Table 1). We followed the same procedure for parenthood, identifying the two groups of parents and non-parents during the observation window ('childbearing' columns of Table 1). The four groups 
differ in compositional characteristics. We are specifically interested in uncovering the main characteristics associated with entry into marriage and parenthood by the age of 30 and how compositionally similar (or different) the two groups of wives and mothers are.

\section{$>$ INSERT TABLE 1 ROUGHLY HERE $<<$}

Examining first the bottom part of Table 1, we see that within our sample the majority $(63.5 \%)$ of women who get married also become mothers before the end of our period of observation. In the same vein, $53.8 \%$ of women who become mothers by the age of 30 are married. As we expected, therefore, at the descriptive level we find a positive association between marriage and childbearing.

In line with the most recent official U.S. statistics (U.S. Census Bureau), the median age at conception of the first child, which is 26.67 , is smaller than the median age at first marriage (28.08).

Compared to those who have not had children, young mothers are more likely to come from a low socioeconomic status, measured in terms of parental education and family income at Wave I. Moreover, they are less likely to grow up in a family with both biological parents and they have, on average, more siblings. Although these patterns are slightly traceable in the comparison between (still) single and married women as well, they are much less pronounced. Therefore, a low socioeconomic status is more likely to be associated with early motherhood than early marriage. Young adults coming from a religious family background are conversely slightly more likely to marry early as opposed to becoming young mothers. However, the main difference between the groups of 'wives' and 'mothers' rests with race. The percentage of Blacks among early mothers is higher than women with no children, but it is definitely lower among marrieds than singles. We do not observe substantial differences across groups in the number of friends at Wave III; each group has an average number of friends of roughly 0.8 and an average number of peers of roughly 3.5 . Therefore, these results do not provide evidence of substantial differences in the number of network relationships across groups.

\section{Results of the two independent hazard models for marriage and parenthood}

Estimates of the two independent hazard models for the risk of getting married and becoming a parent are shown in Table 2. Net of the baseline hazard and the control variables' effect, we find no cross- 
friend influences on an individual's risk of getting married. Specifically, an increasing number of friends who enter matrimony does not raise an individual's risk of marrying. We do, however, find a significant contextual effect, evident from the positive effect on that risk of an increasing number of peers (i.e., non-friends, former schoolmates) who get married. Therefore, our first hypothesis does not seem to be supported by the data. On the other hand, the fact that former schoolmates influence an individual's propensity to marry is very much in line with Hernes's (1972) findings, showing that the greater the share of married peers within a cohort, the higher the risk of getting married for individuals in such a cohort. He specifically argues that people are affected by social pressure exerted by peers of roughly the same age (like in our case, because we define as an individual's peers as her former schoolmates) because social interaction is assumed to be age-graded. Of course, besides social pressure, other confounding contextual forces might be at play, such as a pure aging effect, or the simple fact that former schoolmates come from the same geographical area or same socio-economic status, which might shape each individual's propensity to marry at the same time.

\section{$>$ INSERT TABLE 2 ROUGHLY HERE $<<$}

Going back to Table 2, we can see that our findings support our second hypothesis, since results of the hazard model for fertility show that an individual is more at risk of becoming a mother when the number of friends who are parents increases. This finding is in line with previous studies that find evidence of social interaction effects on fertility decision-making among siblings (Lyngstad \& Prskawetz, 2010), co-workers (Hensvik \& Nilsson, 2010), and dyads of friends (Balbo \& Barban, 2014). No contextual effects are found on the propensity to have the first child. Different from marriage, peers' behavior does not seem to be associated with an individual's fertility decision.

While marital choices seem to be affected by contextual factors, and maybe a general social pressure stemming from the fact that an increasing number of coetaneous people are married, the decision to become a parent is clearly more influenced by friends' behavior. This difference might rest with the fact that the latter choice brings about much more uncertainty, as well as higher costs. Life changes associated with the transition to parenthood might be better borne and faced if they are 
shared with friends, which can be a great source of information. Synchronizing such a transition with friends, moreover, can be a good strategy to reduce relational costs by minimizing the risk of being left behind.

Let us now turn to the baseline hazard and the effect of our control variables on the risk of marrying and becoming a parent. The duration pattern, as a quadratic function of an individual's age, shows a clear curvilinear shape for both family-formation behaviors. The positive effect of older age on marriage and first birth rate is coupled with a small negative effect of age squared, indicating that the effect of an individuals' age becomes weaker or negative the older the individual is. We observe an interesting, substantial difference in how race influences the two risks of getting married and having a child. While Black women are more likely to become mothers earlier than non-Black women, it is the opposite for the risk of getting married, with non-Black women more likely to experience an early marriage than Blacks, in line with previous research (Edin \& Reed, 2005). We also find that the higher the number of siblings, the younger the age at first birth, also confirming previous results (e.g., Rijken \& Liefbroer, 2009). No similar effect is found for the marital decision.

Turning to the economic situation of the family of origin, we observe that women from lowincome families have a higher risk of becoming parents sooner than those from a higher income family. This effect on the propensity to marry is not as clear-cut. Specifically, only people coming from a very disadvantaged family have a higher risk of getting married. This finding is in line with previous research (Uecker \& Stokes, 2008). As far as parental education and family type are concerned, we find that they shape only the risk of becoming a parent, and not marriage. People who have more-educated parents seem to have the first child later than those who come from a lesseducated family. Presumably, this effect is the result of the fact that the first group of individuals is more likely to stay in education longer, thereby delaying the entry into parenthood (Rijken \& Liefbroer, 2009). Individuals who grew up with both biological parents become parents later than those who resided in a step- or single-parent family. On the other hand, parental religiosity only affects the risk of getting married. As expected and in line with existing research (Thornton et al., 1992), a 
religious family background increases the propensity to marry earlier. Finally, the positive close link between marital and childbearing decisions is evident from the fact that married women have a much higher risk of becoming mothers. Whether this effect captures only a causal relationship between the two decisions (from marriage to childbearing), or is the result of a spurious association, cannot be concluded using the model shown in Table 2. We therefore apply a multiprocess model to overcome this issue, controlling for possible unobserved heterogeneity common to the two processes.

\section{Results of the multiprocess model}

Tables 3 and 4 report the respective estimates of the fixed and the random parts of the multilevel process we estimated to take into account possible unobserved heterogeneity at the individual level affecting both the risk of entry into marriage and that of parenthood.

If we compare the estimates of the covariates' coefficients of the multiprocess model (Table 3) with those of the two independent models, we cannot find substantial differences in both processes. The effect of the control variables and the baseline hazard is consistent, although low parental income seems to have a slightly stronger impact on the propensity to marry in the multiprocess model. The only relevant, but expected, change is in the effect of marital status on the risk of having a child. Table 4 shows a strong, positive correlation between the random effects of the two hazards, fully supporting our third hypothesis, that the risk of entry into marriage and parenthood is partially determined by common individual factors, also found in previous studies (e.g., Aassve et al., 2006; Baizan et al.. $2003,2004)$. As a consequence of the presence of a significant and rather high common unobserved heterogeneity (i.e., there are time-invariant subjective factors that affect both an individual's propensity to marry as well as the one to become a mother. Table 4), the direct and independent effect of marital status on the risk of first birth is reduced, although it remains strong and highly significant (Table 3). This suggests that marriage has its own independent effect on childbearing, being perceived by a woman as the most appropriate setting in which to become a mother.

$>>$ INSERT TABLE 3 AND 4 ROUGHLY HERE $<<$

Our finding that the correlation between the unobserved heterogeneity of the two hazards is 
strong and positive indicates that transition into marriage and transition to parenthood can be considered a joint choice of a couple's unique underlying family-formation strategy. The presence of this positive correlation between these two decisions, moreover, suggests that those women who marry early likely become early mothers as well.

\section{CONCLUDING REMARKS}

This study extended existing research on the impact of social interaction effects on demographic behavior by examining the extent to which friends' and peers' behavior influences the entry into marriage and parenthood. Using the Add Health survey, we first engaged in independent discretetime event history models with random effects at the individual level to estimate the risk of entry into marriage and parenthood. In a second step, we implemented a multiprocess model (Baizan et al., 2003; Steele et al., 2005) to test empirically whether an individual's underlying marital and parenthood decisions were jointly taken.

By exploiting the Add Health network design, we were able to distinguish an individual's friends from peers (i.e., former schoolmates not defined as friends who simply shared the same social context). This provided us with the unique opportunity to estimate both cross-friend and cross-peer effects on the hazard of entry into marriage and parenthood in addition to separate true cross-friend influences from contextual effects.

Results showed a strong and significant cross-friend effect on entry into parenthood, with no impact of friends for marriage. In fact, having an increasing number of friends who get married does not seem to raise an individual's propensity to marry. To reflect upon and interpret these findings, we turn to the first contribution of this study, which was the further theoretical development of three potential theoretical mechanisms - social influence, social learning, and cost-sharing dynamics - to describe how social interaction might differently affect entry into marriage and parenthood. Marriage and parenthood are associated with very different levels of uncertainty and costs. A central finding was that since peers have a stronger impact on marriage, social influence or pressure appears to be the central explanatory mechanism. For entry into parenthood, however, cross-friend effects were 
paramount, which was related to social learning, but also cost-sharing dynamics and the benefit of 'pooling' parental resources in the form of network externalities.

A second contribution was empirical in nature, which is the fact that we not only considered the entry into marriage and parenthood as two independent transitions, which is often the case in existing literature, but also modeled them as two joint outcomes of a common underlying family-formation strategy. This is in line with existing literature, which has demonstrated that marital and fertility decisions are highly interdependent, since they are both simultaneously affected by common unobserved inter-individual heterogeneity (Aassve et al., 2006; Steele et al., 2006). By focusing on a pathway in which an individual first experiences marriage followed by parenthood, we adopted a multiprocess model to uncover a positive correlation between unobserved subjective factors that simultaneously affected the decision to marry and become a parent.

Although the current study offers new insights, we are also aware of some of its limitations. First, in a society were cohabitation is increasingly widespread (Smock, Casper \& Wyse, 2008), the fact that we could not take this type of union into account inevitably leads to a somewhat incomplete picture of the broader family formation process among American youth. The lack of cross-friend effects on marriage might indeed also be the result of the spread of cohabitation, which might operate as a competing event. It would be desirable for further research on social interaction to take this transition into account, which was not possible in the current study. Other minor limitations are related to some of the data constraints that we faced, such as the small sample size, the inability to carry out recurrent event models, or the difficulty in finding a valid exclusion restriction in our multiprocess model that could allow us to also look into the reverse path of the effect of prior childbearing on marriage. These are all aspects that we hope future research can overcome, hopefully with the use of new network-based panel data, which at the moment, with few exceptions like the Add Health study, are still lacking. In spite of the abovementioned limitations, we believe this study is a first, important step towards a more thorough knowledge of the different ways that social interaction can impact diverse life-course transitions. 


\section{References}

Aassve, A., Burgess, S., Propper, C., \& Dickson, M. (2006). Employment, family union and childbearing decisions in Great Britain. Journal of the Royal Statistical Society: Series A (Statistics in Society), 169(4), 781-804. doi: 10.1111/rssa.2006.169.issue-4

Ali, M. M., and Dwyer D. S. (2010). Estimating peer effects in sexual behavior among adolescents. Journal of Adolescence, 34(1), 183-190. doi: 10.1016/j.adolescence.2009.12.008

Amato, P., Landale, N., \& Havasevich-Brooks, T. (2008). Precursors of young women's family formation pathways. Journal of Marriage and Family, 70(5), 1271-1286. doi: 10.1111/j.17413737.2008.00565.x

Aparicio Diaz, B., Fent, T., Prskawetz A., \& Bernardi, L. (2011). Transition to Parenthood: The Role of Social Interaction and Endogenous Networks. Demography, 48(2), 559-579. doi: $10.1007 / \mathrm{s} 13524-011-0023-6$

Baizán, P., Aassve, A., \& Billari, F.C. (2003). Cohabitation, marriage, and first birth: The interrelationship of family formation events in Spain. European Journal of Population, 19(2), 147169. doi: 10.1023/A:1023343001627

Baizán, P., Aassve, A., \& Billari, F.C. (2004). The interrelations between cohabitation, marriage and first birth in Germany and Sweden. Population and Environment, 25(6), 531-561. doi: 10.1023/B:POEN.0000039064.65655.3b

Balbo, N. \& Barban, N. (2014). Does fertility behavior spread among friends?. American Sociological Review, 79(3), 412-431. doi: 10.1177/0003122414531596

Balbo, N. \& Mills, M. (2011). The effects of social capital and social pressure on the intention to have a second or third child in France, Germany, and Bulgaria, 2004-05. Population Studies, 65(3), 335-351. doi: 10.1080/00324728.2011.579148

Beck, U. \& Beck-Gernsheim, E. (2002). Individualisation: Institutionalized individualism and Its Social and Political Consequences. London: Sage.

Behrman, J.R., Kohler, H.-P., \& Watkins, S.C. (2002). Social networks and changes in contraceptive use over time: Evidence from a longitudinal study in rural Kenya. Demography, 39(4), 713-736. doi: $10.1353 /$ dem.2002.0033

Bernardi, L. (2003). Channels of social influences on reproduction. Population Research and Policy Review, 22(5-6),527-555. doi: 10.1023/B:POPU.0000020892.15221.44

Bernardi, L., Keim, S., \& von der Lippe, H. (2007). Social influences on fertility: a comparative mixed methods study in eastern and western Germany. Journal of Mixed Methods Research, 1(1), 23-47. doi: 10.1177/2345678906292238

Billari, F. C., Prskawetz, A., Diaz, B.A., \& Fent, T. (2007). The "wedding-ring": An agent-based marriage model based on social interaction. Demographic Research, 17(3), 59-81. doi: $10.4135 / 9781446261088$

Bongaarts, J., \& Watkins, S. (1996). Social interactions and contemporary fertility transitions. Population and Development Review, 22(4), 639-682. doi: 10.2307/2137804

Brien, M.J., Lillard, L.A., \& Waite, L.J. (1999). Interrelated Family-Building Behaviors: Cohabitation, Marriage, and Nonmarital Conception. Demography, 36(4), 535-551. doi: $10.2307 / 2648089$

Bumpass, L.L. (1990). What's happening to the family? Interactions between demographic and institutional change. Demography, 27(4), 483-490. Retrieved from http://www.jstor.org/stable/2061566 
Calvó-Armengol, A., Patacchini, E., \&. Zenou, Y (2009). Peer Effects and Social Networks in Education. Review of Economic Studies, 76(4), 1239-1267. doi: 10.1111/j.1467937X.2009.00550.x

Cappellari, L. \& Tatsiramos, K. (2011). Friends' network and job finding rates. CESifo Working Paper Series No. 3243

Chang, E.S., Greenberger, E., Chen, C., Heckhausen, J., \& Farruggia, S.P. (2010). Nonparental Adults as Social Resources in the Transition to Adulthood. Journal of Research on Adolescence, 20(4), 1065-1082. doi: 10.1111/j.1532-7795.2010.00662.x

Cherlin, A. (2005). American Marriage in the Early Twenty-First Century. The Future of Children, 15(2), 33-55. doi: 10.1353/foc.2005.0015

Christakis N.A., \& Fowler, J.H. (2007). The Spread of Obesity in a Large Social Network Over 32 Years. New England Journal of Medicine, 357(4), 370-379. doi: 10.1056/NEJMsa066082

Cialdini, R.B., Reno, R.R., \&. Kallgren, C.A. (1990). A focus theory of normative conduct: Recycling the concept of norms to reduce littering in public places. Journal of Personality and Social Psychology, 58(6), 1015-1026. doi: 10.1037/0022-3514.58.6.1015

Ciliberto, F., Miller, A., Nielsen, H., \& Simonsen, M.. (2010). Playing the Fertility Game at Work: An Equilibrium Model of Peer Effects. CEPR Discussion Paper No. DP9429

Current Population Survey, U.S. Census Bureau. http://www.census.gov/cps/

Drewianka, S. (2003). Estimating Social Effects in Matching Markets: Externalities in Spousal Search. Review of Economics and Statistics, 85(2), 409-423. doi: 10.1162/003465303765299909

Edin, K. \& Reed, J.M. (2005). Why Don't They Just Get Married? Barriers to Marriage among the Disadvantaged. Future of Children, 15(2), 117-137. doi: 10.1353/foc.2005.0017

Elwert, F., \&. Christakis, N.A. (2008). Wives and Ex-Wives: A New Test for Homogamy Bias in the Widowhood Effect. Demography, 45(4), 851-873. doi: 10.1353/dem.0.0029

Festinger, L. (1954). A Theory of Social Comparison Processes. Human Relations, 7(2), 117-40. doi: $10.1177 / 001872675400700202$

Fletcher, J.M. (2011). Peer influences on adolescent alcohol consumption: evidence using an instrumental variables/fixed effect approach. Journal of Population Economics, doi: 10.1007/s00148-011-0365-9.

Haurin, R.J., \& Mott, F.L. (1990). Adolescent sexual activity in the family context: The impact of older siblings. Demography, 27(4), 537-557. doi: 10.2307/2061569

Hensvik, L., \& Nilsson, P. (2010). Business, buddies and Babies. IFAU Working Paper.

Hernes, G. (1972). The process of entry into first marriage. American Sociological Review, 37(2), 47-82. Retrieved from http://www.jstor.org/stable/2094025

Hobcraft, J., \& Kiernan, K. (1995). Becoming a parent in Europe. In EAPS-IUSSP (Ed.), European Population Conference (Vol. 1, pp. 27-65). Milan: Franco Angeli.

Huang, P., Smock, P.J., Bergstrom-Lynch, C., \& Manning, W. (2011) 'He Says, She Says': Gender and Cohabitation. Journal of Family Issues, 32(7), 876-905. doi: 10.1177/0192513X10397601

Joyner, K., Peters, H.E., Hynes, K., Sikora, A., Taber, J.R., \& Rendall, M.S. (2012). The Quality of Male Fertility Data in Major U.S. Surveys, Demography, 49(1), 101-124. doi: 10.1007/s13524011-0073-9

Katz, M.L., \& Shapiro, C. (1985). Network externalities, competition, and compatibility. American Economic Review, 75(3), 424-440. Retrieved from http://www.jstor.org/stable/1814809 
Keim, S., Klärner, A., \& Bernardi, L. (2009). Qualifying social influence on fertility intentions: composition, structure, and meaning of fertility-relevant social networks. Current Sociology, 57(6), 1-20, 2009. doi: 10.1177/0011392109342226

Kennedy, S., \& Bumpass, L.L. (2008). Cohabitation and children's living arrangements: New estimates from the United States. Demographic Research, 19(47), 1663-1692. doi: 10.4054/DemRes.2008.19.47

Kiernan, K. (1999). Childbearing outside marriage in Western Europe. Population Trends, 98, 11-20. Retrieved from http://europepmc.org/abstract/med/10658241

Knecht, A., Baerveldt, C., Snijders, T.A.B., Steglich, C., \& Raub, W. (2010). Friendship and Delinquency in Early Adolescence: A study of selection and influence effects. Social Development, 19, 494-514. doi: 10.1111/j.1467-9507.2009.00564.x

Kohler, H.-P. (2001). Fertility and Social Interaction. An Economic Perspective. Oxford: Oxford University Press.

Kohler, H.-P., Billari, F.C., \& Ortega, J.A. (2002). The emergence of lowest-low fertility in Europe during the 1990s. Population and Development Review, 28(4), 641-681. doi: 10.1111/j.17284457.2002.00641.x

Kohler, H.-P., Billari, F.C., \& Ortega, J.A. (2006). Low fertility in Europe: Causes, implications and policy options. In F. R. Harris (Ed.), The Baby Bust: Who will do the Work? Who Will Pay the Taxes? (pp. 48-109). Lanham, MD: Rowman and Littlefield Publishers.

Kohler, H.-P., Behrman J.R., \& Watkins, S.C. (2001). The density of social networks and fertility decisions: evidence from S. Nyanza District, Kenya. Demography, 38(1), 43-58. doi: 10.1353/dem.2001.0005

Kravdal, Ø. (2001). The High Fertility of College Educated Women in Norway: An Artefact of the Separate Modelling of Each Parity Transition. Demographic Research, 5(6), 187-216. doi: 10.4054/DemRes.2001.5.6

Kuziemko, I. (2006). Is Having Babies Contagious? Fertility Peer Effects Between Adult Siblings. Princeton University Working Paper.

Lazarsfeld, P.F., \& Merton, R.K. (1954). Friendship as Social Process. In Monroe Berger, Theodore Abel and Charles Page (Ed.), Freedom and Control in Modern Society (pp. 18-66). New York: Octagon.

Lesthaeghe, R. \& Surkyn, J. (1988). Cultural dynamics and economic theories of fertility change. Population and Development Review, 14(1), 1-45. doi: 10.2307/1972499

Liefbroer, A.C. (1999). From youth to adulthood: Understanding changing patterns of family formation from a life course perspective. In L. J. G. Van Wissen and P. A. Dykstra (Ed.), Population Issues. An Interdisciplinary Focus (pp.53-86). New York: Kluwer Academic/Plenum Publishers.

Liefbroer, A.C., \& Billari, F.C. (2010). Bringing Norms Back In: A Theoretical and Empirical Discussion of Their Importance for Understanding Demographic Behaviour. Population, Space and Place, 16(4), 287-305. doi: 10.1002/psp.552

Lillard, L.A. (1993). Simultaneous equations for hazards: Marriage duration and fertility timing. Journal of Econometrics, 56(1-2), 189-217. doi: 10.1016/0304-4076(93)90106-F

Lillard, L.A., Brien, M.J., \& Waite, L.J. (1995). Premarital Cohabitation and Subsequent Marital Dissolution: A Matter of Self-Selection? Demography, 32(3), 437-457. doi: 10.2307/2061690

Lyngstad, T.H., \& Prskawetz, A. (2010). Do siblings' fertility decisions influence each other? Demography, 47(4), 923-934. doi: 10.1007/BF03213733 
Manning, W.D. (2005). Cohabitation, Marriage, and Entry into Motherhood. Journal of Marriage and Family, 57(1), 191-200. doi: 10.2307/353827

Manning, W.D. \& Smock, P.J. (1995). Why Marry? Transitions to Marriage Among Cohabitors. Demography, 32(4), 509-520. doi: 10.2307/2061671

Manning, W.D., Longmore, M.A., \& Giordano, P.C. (2007). The Changing Institution of Marriage: Adolescents' Expectations to Cohabit and to Marry. Journal of Marriage and Family, 69(3), 559575. doi: 10.1111/j.1741-3737.2007.00392.x

Manski, C.F. (1995). Identification problems in social sciences. Harvard: Harvard University Press.

Manski, C.F., \& Mayshar, J. (2003). Private incentives and social interactions: Fertility puzzles in Israel. Journal of the European Economic Association, 1(1), 181-211. doi: $10.1162 / 154247603322256800$

Manski, C.F. (1993). Identification of Endogenous Social Effects: The Reflection Problem. The Review of Economic Studies, 60(3), 531-42. Retrieved from http://www.jstor.org/stable/2298123

McPherson, J.M., Smith-Lovin, L., \& Cook, J.M. (2001). Birds of a Feather: Homophily in Social Networks. Annual Review of Sociology, 2, 415-44. doi: 10.1146/annurev.soc.27.1.415

Mercken, L, Snijders, T.A.B., Steglich, C., \& de Vries, H. (2009). Dynamics of Adolescent Friendship Networks and Smoking Behavior: Social Network Analyses in Six European Countries. Social Science and Medicine, 69(10), 1506-1514. doi: 10.1016/j.socscimed.2009.08.003

Mills, M., Rindfuss, R.R., McDonald, P., \& te Velde, E. (2011). Why do people postpone parenthood? Reasons and social policy incentives. Human Reproduction Update, 17(6), 848-860. doi: 10.1093/humupd/dmr026

Montgomery, M.R., \& Casterline, J.B. (1996). Social Influence, Social Learning, and New Models of Fertility. In J. Casterline, Lee R., \& Foote K. (Ed.). Fertility in the United States: New Patterns, New Theories (pp. 87-99). Supplement to Population and Development Review, 22, 100-107. Retrieved from http://www.popline.org/node/302747

National Vital Statistics System National, CDC/NCHS. http://www.cdc.gov/nchs/nvss.htm

Nazio, T., \& Blossfeld, H.-P. (2003). The Diffusion of Cohabitation among Young Women in West Germany, East Germany and Italy. European Journal of Population, 19(1), 47-82. Retrieved from http://www.jstor.org/stable/20164213

Pastor-Satorrás, R., \& Vespignani, A. (2001). Epidemic Spreading in Scale-Free Networks. Physical Review Letters, 86(14), 3200-3203. Retrieved from https://journals.aps.org/prl/abstract/10.1103/PhysRevLett.86.3200

Patacchini, E., \& Zenou, Y. (2012). Juvenile Delinquency and Conformism. Journal of Law, Economics, and Organization, 1, 1-31. doi: 10.1093/jleo/ewp038

Pollard, M.S., Tucker, J.S., Green, H.D., Kennedy, D., \& Go, M.-H. (2010). Friendship Networks and Trajectories of Adolescent Tobacco Use. Addictive Behaviors, 35(7), 678-685. doi: 10.1016/j.addbeh.2010.02.013

Rasbash, J., Steele, F., Browne, W.J., \& Prosser, B. (2004). A User's Guide to MLwiN, Version 2.0. London: Institute of Education.

Rijken, A.J., \& Liefbroer, A.C. (2009). Influences of the family of origin on the timing and quantum of fertility in the Netherlands. Population Studies, 63(1), 71-85. doi: $10.1080 / 00324720802621575$

Rindfuss, R.R., Morgan, S.P., \& Swicegood, G. (1988). First Births in America: Changes in the Timing of Parenthood. Berkeley: University of California Press. 
Ryan, S., Franzetta, K., Schelar, E., \& Manlove, J. (2009). Family structure history: links to relationship formation behaviors in young adulthood. Journal of Marriage and Family, 71(4), 935-953. doi: 10.1111/j.1741-3737.2009.00645.x

Santelli, J.S., \& Melnikas, A.J. (2010). Teen Fertility in Transition: Recent and Historic Trends in the United States. Annual Review of Public Health, 31, 371-383. doi: 10.1146/annurev.publhealth.29.020907.090830

Schoen, R., Landale, N.S., \& Daniels, K. (2007). Family transitions in young adulthood. Demography, 44(4), 807-820. doi: 10.1353/dem.2007.0044

Smock, P.J., Casper, L., \& Wyse, J. (2008). Nonmarital cohabitation: current knowledge and future directions for research. Report 08-648, Population Studies Center, University of Michigan.

Smock, P.J., \& Greenland, F.S. (2010). Diversity in Pathways to Parenthood: Patterns, Implications, and Emerging Research Directions. Journal of Marriage and Family, 72(3), 576-93. doi: 10.1111/j.1741-3737.2010.00719.x

Stanley, S. M., Kline Rhoades, G.. \& Markman, H. J. (2006). Sliding Versus Deciding: Inertia and the Premarital Cohabitation Effect. Family Relations, 55(4), 499-509. doi: 10.1111/j.17413729.2006.00418.x

Steele, F., Kallis, C., Goldstein, H., \& Joshi, H. (2005). The relationship between childbearing and transitions from marriage and cohabitation in Britain. Demography, 42(4), 647-673. doi: 10.1353/dem.2005.0038

Steele, F., Joshi, H., Kallis, C., \& Goldstein, H. (2006). Changing compatibility of cohabitation and childbearing between young British women born in 1958 and 1970. Population Studies, 60(2), 137-152. Retrieved from http://www.jstor.org/stable/27643377

Thornton, A., Axinn, W.G., \& Hill, D.H. (1992). Reciprocal effects of religiosity, cohabitation, and marriage. American Journal of Sociology, 98(3), 628 - 651. doi: 10.1086/230051

Thomson, E., Winkler-Dworak, M., Spielauer, M., \& Prskawetz, A. (2012). Union Instability as an Engine of Fertility? A Microsimulation Model for France. Demography, 49(1), 175-195. doi: 10.1007/s13524-011-0085-5

Topa, G. (2001). Social Interactions, Local Spillovers and Unemployment. Review of Economic Studies, 68(2), 261-95. Retrieved from http://www.jstor.org/stable/2695929

Uecker, J.E., \& Stokes, C.E. (2008). Early Marriage in the United States. Journal of Marriage and Family, 70(4), 835-846. doi: 10.1111/j.1741-3737.2008.00530.x

Upchurch, D.M., Lillard, L.A., \& Panis, C.W.A. (2002). Nonmarital Childbearing: Influences of Education, Marriage, and Fertility. Demography, 39(2), 311-29. doi: 10.1353/dem.2002.0020 
Tables

Table 1. Descriptive statistics of the sample in percentage

\begin{tabular}{|c|c|c|c|c|c|}
\hline & & age & Child & $\operatorname{aring}$ & Total \\
\hline & Single & Married & Childless & Mothers & \\
\hline Parent education & & & & & \\
\hline Less than high school & 10.2 & 10.4 & 8.0 & 13.2 & 10.3 \\
\hline High school or equivalent & 31.8 & 34.1 & 27.7 & 38.8 & 32.6 \\
\hline Some college & 18.2 & 20.3 & 18.9 & 19.0 & 19.0 \\
\hline College education or more & 30.5 & 26.1 & 37.8 & 17.6 & 28.8 \\
\hline Unknown & 9.3 & 9.1 & 7.5 & 11.4 & 9.2 \\
\hline Family type & & & & & \\
\hline Living with both parents at Wave I & 53.5 & 56.4 & 63.1 & 43.9 & 54.6 \\
\hline Living in a step family at Wave I & 9.3 & 10.7 & 7.5 & 12.8 & 9.8 \\
\hline Living with single mother at Wave I & 30.0 & 27.5 & 24.4 & 34.9 & 29.1 \\
\hline Living with single father at Wave I & 2.3 & 1.8 & 1.6 & 2.7 & 2.1 \\
\hline Living in other typology of family at Wave I & 4.9 & 3.6 & 3.5 & 5.6 & 4.4 \\
\hline Parental religiosity & & & & & \\
\hline Low/not religious & 65.9 & 63.3 & 62.8 & 67.6 & 65.9 \\
\hline High & 34.1 & 36.7 & 37.2 & 32.4 & 35.1 \\
\hline Race & & & & & \\
\hline Hispanic & 9.5 & 11.1 & 9.3 & 11.1 & 10.1 \\
\hline Black & 33.6 & 13.5 & 21.9 & 31.2 & 26.1 \\
\hline Asian & 5.6 & 2.5 & 6.2 & 2.3 & 4.5 \\
\hline White & 51.3 & 72.9 & 62.5 & 55.5 & 59.4 \\
\hline Parental Income & & & & & \\
\hline 1st quintile & 23.2 & 21.8 & 17.6 & 29.3 & 22.6 \\
\hline 2nd quintile & 20.5 & 20.0 & 16.5 & 25.3 & 20.3 \\
\hline
\end{tabular}




\begin{tabular}{l|cc|cc|c|} 
3rd quintile & 20.3 & 23.9 & 21.7 & 21.6 & 21.6 \\
4th quintile & 17.4 & 19.1 & 20.3 & 15.1 & 18.1 \\
5th quintile & 18.8 & 15.2 & 24.0 & 8.8 & 17.4 \\
Average number of siblings & 1.53 & 1.57 & 1.49 & 1.70 & 1.55 \\
Average number of friends (Min: 0; Max: 6) & 0.76 & 0.80 & 0.78 & 0.76 & 0.78 \\
Average number of peers (Min: 0; Max: 10) & 3.65 & 3.50 & 3.41 & 3.57 & 3.51 \\
Mothers & 32.7 & 63.5 & - & - & 44.2 \\
Married & - & - & 24.5 & 53.8 & 37.5 \\
Median age at first marriage & - & 28.08 & - & - & - \\
Median age at first birth & - & - & - & 26.67 & - \\
Number of women observed & 1190 & 713 & 1061 & 842 & 1903 \\
\hline
\end{tabular}


Table 2. Coefficient estimates (fixed part only) of two independent complementary log-log (cloglog) discrete time hazards of getting married and becoming a parent

Marriage

$B \quad S E B \quad B \quad S E B$

Constant

Age

Age squared

Black (ref: non-Black)

Intact family (other types of family)

$1^{\text {st }}$ income quintile (ref: $5^{\text {th }}$ income quintile)

$2^{\text {nd }}$ income quintile

0.23

$3^{\text {rd }}$ income quintile

0.15

$4^{\text {th }}$ income quintile

0.10

$-0.01$

Number of friends

Parents went at least to college (ref: lower education)

Parental religiosity (ref: no)

Number of siblings

Married (ref: non married)

Number of friends who became parents

Number of peers who became parents

Number of friends who got married

Number of peers who got married

$\mathrm{N}$

$-0.13$

0.53

0.02

0.14

0.06

0.14

$-0.48 * * * \quad 0.11$

$-0.19 \quad 0.12$

$0.11 * * \quad 0.04$

$1.55^{* * *} \quad 0.13$

$0.23 * 0.09$

$0.05 \quad 0.04$
$0.15 \quad 0.11$

$0.10^{*} \quad 0.05$

Number of spells 
Table 3. Coefficient estimates (fixed part only) of a multiprocess model composed by two complementary log-log (cloglog) discrete time hazards of getting married and becoming a parent Marriage Childbearing

Constant

Age

Age squared

Black (ref: non-Black)

Intact family (other types of family)

$1^{\text {st }}$ income quintile (ref: $5^{\text {th }}$ income quintile)

$2^{\text {nd }}$ income quintile

$3^{\text {rd }}$ income quintile

$4^{\text {th }}$ income quintile

Number of friends

Parents went at least to college (ref: lower education)

Parental religiosity (ref: no)

Number of siblings

Married (ref: non married)

Number of friends who became parents

Number of peers who became parents

Number of friends who got married

Number of peers who got married

$\mathrm{N}$

Number of spells
$B \quad S E B \quad B \quad S E B$

$-31.79 * * * \quad 3.46-20.90 * * * \quad 1.87$

$$
2.06 * * * \quad 0.32 \quad 1.43 * * * \quad 0.18
$$$$
\begin{array}{llll}
-0.04 * * * & 0.01 & -0.03 * * * & 0.01
\end{array}
$$$$
\begin{array}{llll}
-1.45^{* * *} & 0.22 & 0.31^{*} & 0.12
\end{array}
$$

$\begin{array}{llll}0.01 & 0.15 & -0.34 * * & 0.11\end{array}$

$0.63 * * \quad 0.24 \quad 0.86^{* * *} \quad 0.20$

$\begin{array}{llll}0.31 & 0.22 & 1.00 * * * & 0.19\end{array}$

$\begin{array}{llll}0.20 & 0.20 & 0.78 * * * & 0.19\end{array}$

$\begin{array}{llll}0.12 & 0.20 & 0.50 * & 0.20\end{array}$

$\begin{array}{llll}-0.02 & 0.05 & -0.05 & 0.04\end{array}$

$\begin{array}{llll}-0.17 & 0.14 & -0.48 * * * & 0.11\end{array}$

$\begin{array}{llll}0.46 * * * & 0.13 & -0.17 & 0.11\end{array}$

$\begin{array}{llll}0.03 & 0.05 & 0.11 * * & 0.04\end{array}$

$1.20 * * * \quad 0.13$

$0.24 * * \quad 0.10$

$0.06 \quad 0.04$

$0.15 \quad 0.111$

$0.10^{*} \quad 0.051$ 
Table 4. Estimated random-effect covariance matrix of the multiprocess model

\begin{tabular}{lcc}
\hline & Marriage & Childbearing \\
\hline Marriage & 1 & \\
Childbearing & $0.56(0.10)^{* * *}$ & 1 \\
& Corr. $=0.56$ & \\
\hline
\end{tabular}

${ }^{*} p<0.05^{* *} p<0.01{ }^{* * *} p<0.001$ from Wald test

Note: The reported values are the estimated variance of each random effect. The off-diagonal cell represents the covariance with standard error in parentheses and correlation between the two random effects. 